\title{
PORTEÑAS BUENAS MOZAS: CORAZÓN Y BELLEZA EN LA CONSTRUCCIÓN DE LA MUJER EN LA NARRATIVA DE SALVADOR REYES ${ }^{1}$
}

Porteñas buenas mozas: Heart and beauty in the construction of women in the narrative of Salvador Reyes

\author{
Alexis Candia-Cáceres* \\ Oscar Rosales Neira** \\ Patricio Landaeta***
}

Resumen

Este artículo propone un estudio de la mujer en los textos que conforman la narrativa porteña de Salvador Reyes: El café del puerto (1926), Piel nocturna (1936), Mónica Sanders (1951) y Valparaíso, puerto de nostalgia (1955). Para esto se plantea analizar la construcción del sujeto femenino a partir de la noción de "corazón y belleza" propuesta por Rimbaud, la que, contra la mirada falogocéntrica del Chile de la primera parte del siglo XX, termina generando líneas de fuga que abren posibilidades de transgresión y ruptura en el orden de las familias. Asimismo, se realizan ciertas conexiones intertextuales necesarias para la comprensión del componente disruptivo de la representación de la mujer en la escritura de Reyes.

Palabras clave: Salvador Reyes. Narrativa. Mujer. Valparaíso. Corazón y belleza.

Abstract

The article proposes a review of the role of women in the works that shape Salvador Reyes' narrative of Valparaíso: El café del puerto (1926), Piel nocturna (1936), Mónica Sanders (1951) and Valparaíso, puerto de nostalgia (1955). The construction of the female subject follows Rimbaud's notion of "heart and beauty". This notion counters the phallocentric bias prevalent in Chile in the early 20th century by setting lines of flight that open possibilities of transgression within the order of the family. In addition, this article proposes intertextual connections necessary for understanding the disruptive component of the representation of women in Reyes' writing.

Key words: Salvador Reyes. Narrative. Woman. Valparaíso. Heart and beauty.

\section{INTRODUCCIÓN}

Porteñas buenas mozas es un título que alude al vals chileno La joya del Pacífico, canción creada por Víctor Acosta a inicios de la década de $1940^{2}$ y popularizada por Lucho Barrios en 1970. La conexión con la canción de Acosta no es antojadiza. Principalmente, porque La joya del Pacífico da cuenta del amor que un marino le declara tanto a Valparaíso como a una "blanca margarita" que parece huir por los cerros, las avenidas, las playas y las plazas del puerto. De allí que en una de las

\footnotetext{
${ }^{1}$ Este texto forma parte del proyecto Fondo del Libro № 55939, en la Línea de Investigación 2014, titulado "Puerto de nostalgia. Representación simbólica del Valparaíso de la primera parte del siglo XX".

${ }^{2}$ Investigaciones recientes le atribuyen la autoría al folclorista Lázaro Salgado.
} 
líneas centrales de la letra se afirme: "Porteña buena moza no me hagas sufrir más". La intensa relación que se produce entre la representación de Valparaíso y la mujer en $L a$ joya del pacífico tiene un estrecho vínculo con la narrativa de Salvador Reyes, debido a que el autor escribe textos donde no solo reconstruye el "imaginario urbano" del puerto, asumiendo una clara vocación "anárquica" en la representación del espacio, sino que crea, además, personajes femeninos que desempeñan roles centrales en el desarrollo de los mismos, tal como acaece con Mónica Sanders en la novela homónima y con Dora Thalberg en Piel nocturna.

Apegándose a la normativa androcéntrica que imperaba en el Chile de inicios y mediados del siglo pasado, Reyes delinea personajes masculinos (Pedro Velazco, Roberto Camerón y Julio Moreno) que evidencian la posición de dominio que debía ejercer el hombre en la sociedad chilena de la primera parte del siglo XX. Los discursos y las acciones que emprenden estos personajes tienden a consolidar la subordinación de la mujer en Valparaíso. Sin embargo, la elaboración de sujetos femeninos independientes, autónomos y libres, como Magdalena Latour o Nelly Bradford, terminan configurando líneas de fuga que transgreden y quiebran la norma sociocultural de la época. Es más, la liberación de las "porteñas buenas mozas" de Reyes llega muchísimo más lejos, por ejemplo, que la realizada por las protagonistas de los relatos de María Luisa Bombal o de Teresa de la Parra. Abordar los componentes disruptivos del sujeto femenino en la narrativa porteña de Reyes, es decir, en el relato El café del puerto (1926) y en las novelas Piel nocturna (1936), Mónica Sanders (1951) y Valparaíso, puerto de nostalgia (1955) constituye el objeto central de este artículo. Para esto es clave considerar la idea de "corazón y belleza" que Reyes toma de Rimbaud, esto es, la adopción de una actitud transgresora que opta por una ruta femenina de desarrollo paralela al matrimonio, la que contraviene, a todas luces, el orden de las familias en Chile.

Reyes tuvo una interesante recepción crítica desde 1930 hasta mediados de 1980, siendo relegado, sin embargo, a una posición secundaria en los últimos años. Desde mediados de los 80 solo es posible encontrar menciones acerca de su obra en estudios generales de la literatura de Valparaíso y un artículo indexado. La narrativa de Reyes fue leída desde la óptica del Marinismo y del Imaginismo. Con relación al marinismo, existe acuerdo en cuanto a la relevancia del mar en la literatura del autor. En Estudios de Literatura Chilena (1938) Domingo Melfi establece que: "Reyes es un evocador de los ambientes de puerto" (19). Mariano Latorre destaca en La literatura de Chile (1941) el vínculo de la lírica de Reyes con el mar: "[...] ensaya en Chile la poesía del mar, a la manera de Rimbaud y de Tristán Corbière” (41). Luis Enrique Délano concuerda con Latorre al plantear que el leitmotiv de la obra de Reyes es el mar: "[...] son las ciudades lejanas, los puertos, las tabernas pintorescas y los hombres libres" (citado en Montes y Orlandi, 191). En Historia y analogía de la literatura chilena (1969) Hugo Montes y Julio Orlandi recalcan que el carácter marino de la literatura de Reyes tiene escasas referencias en la tradición literaria chilena, debido a que desde el trabajo de Alonso de Ovalle los escritores chilenos dieron la espalda al mar. Recién en el siglo XX Guillermo 
Labarca, Vicente Huidobro y Pablo Neruda desarrollan una literatura marítima. El propio Reyes asumió la relevancia del mar en su poética: "El mar es la patria de todos los soñadores" (citado en Montecinos, 7). Reyes manifiesta, además, vocación por construir el imaginario urbano de Valparaíso. Así, Piero Castagneto afirma que el escritor acentúa la faz marítima de Valparaíso. Claudio Solar da a conocer la relevancia que tiene la reconstrucción simbólica del puerto en sus libros: "En El café del puerto y particularmente en Piel nocturna, nos muestra [...] escenas de la vida nocherniega de Valparaíso" (Solar, Contactos, 60). La calificación de "imaginista" con que fue tratada su literatura no despertó igual aceptación en Reyes. Si bien en los primeros momentos de la querella entre Manuel Vega y Alone ${ }^{3}$ aceptó el concepto del "imaginismo" e incluso abogó por una literatura de evasión, más adelante asumió una postura crítica: "Lo de 'imaginista' lo inventó Alone y lo han seguido repitiendo. No tiene sentido [...] Todo escritor es imaginista" (citado en Avaria, 5-6).

El escaso interés en el estudio de la mujer en la narrativa de Reyes se aprecia en que hasta ahora solo se han formulado breves comentarios al respecto. Claudio Solar consigna algunos rasgos erótico-sentimentales de las mujeres que aparecen en sus novelas. Adolfo de Nordenflycht subraya el carácter de estas mujeres: "[...] liberada, segura, coqueta, inaprensible, entregada a vivir el presente" (58). Con relación a Dora, establece que el centro de Piel nocturna está en la historia de una muchacha que: "[...] es agresivamente coqueta, segura de su belleza y dispuesta a vivir al extremo" (68). A partir del espacio axial que ocupa Dora en la novela concluye que su aventura: "[...] ha consistido en el descubrimiento de su piel nocturna" (69). Acerca de Mónica Sanders existen visiones contradictorias. Hernán del Solar tiene una postura crítica: "Es una bella sombra destinada a despertar una pasión poderosa y desaparecer llevándose el secreto" (Del Solar, en línea). Castagneto es capaz de captar, en cambio, la solidez del trabajo de Reyes: "Y para qué hablar de la belleza perfecta y madura o del carácter apasionado y excéntrico de la protagonista de Mónica Sanders" (Castagneto, 99).

De esta forma, es necesario desarrollar un artículo que sea capaz de analizar la construcción de personajes femeninos que, contra la mirada falogocéntrica, terminan transformándose en líneas de fuga que abren nuevas posibilidades de transgresión en la sociedad chilena de la época.

\section{CORAZÓN Y BELLEZA EN EL PUERTO VIEJO}

Rimbaud ejerció una decisiva influencia en la producción literaria de Salvador Reyes, la que tiene, al menos, dos manifestaciones: una directa y otra indirecta. La directa pasa por el homenaje que el escritor chileno hace al poeta francés al titular su primer libro Barco ebrio, título que es una traducción al español del Bateau Ivre, poema extenso de

\footnotetext{
${ }^{3}$ En Salvador Reyes, el gran marinista Montecinos sostiene que mientras Vega abogaba por una literatura que debía estudiar la realidad nacional y reproducirla en sus obras; Alone creía que la labor del escritor era "crear" una obra artística con imaginación, sensibilidad, buen gusto, libre y cargada de fantasía. (7)
} 
evocaciones marinas que Rimbaud envía a Paul Verlaine en 1871. Hay un verso en Bateau Ivre que iluminó, probablemente, la propuesta narrativa de Reyes en la medida que anticipa su predilección por la narración de historias de puertos: "La tempestad bendijo mi despertar marino", $(11)$. La indirecta se relaciona con la influencia que ejerce Una temporada en el infierno (1873) y, específicamente, el poema "La virgen loca. El esposo infernal" en la construcción literaria de la mujer que efectúa Reyes en los textos narrativos que tienen a Valparaíso como espacio literario. En la presentación de Piel nocturna se puede leer: "Quien lea esta novela, desde los arrebatos de la virgen loca hasta la amargura del ángel caído, disfrutará de un relato vívido" (3, cursivas nuestras). La alusión a la "virgen loca" no es azarosa. Principalmente, porque las novelas de Reyes dialogan con la revolución amorosa que plantea el poema de Rimbaud: "Hay que reinventar el amor" (66). Para el "niño terrible" de la lírica francesa esa metamorfosis pasa por la distancia que las mujeres deben tener frente al matrimonio con el fin de adoptar un "amor-pasión" que pueda conectarlas con la fibra romántica de la vida:

Ellas no pueden desear más que una posición segura. Conquistada la posición, corazón y belleza se dejan de lado: solo queda un frío desdén, alimento del matrimonio hoy por hoy. O bien veo mujeres, con los signos de la felicidad, de las que yo hubiera podido hacer buenas camaradas, devoradas desde el principio por brutos sensibles como fogatas (66-67, cursivas nuestras).

Las "porteñas buenas mozas" que atraviesan las novelas de Reyes asumen la relevancia que "corazón y belleza" tienen en la construcción de las relaciones sentimentales, sobreponiendo la pasión, el placer y el sentir amoroso a la suscripción de contratos sociales. Las mujeres de Reyes son figuras transgresoras que contravienen la norma social y cultural de la época. La actitud disidente de las mujeres que habitan este "puerto de nostalgia" se entiende en contraposición al contexto social, histórico y literario de la época en que son publicados sus textos literarios. En la primera parte del siglo XX Chile se encuentra regido por lógicas patriarcales que tienden a escindir las características y las habilidades de mujeres y hombres. En "Masculino y femenino en el imaginario colectivo de comienzos del siglo" Bernardo Subercaseaux establece la oposición que se produce entre lo femenino y lo masculino en el país: "Lo femenino era lo foráneo, la oligarquía afrancesada, el ocio, la especulación [...] Lo masculino en cambio correspondía a la industria, al espíritu emprendedor y guerrero" (248). Los aportes de Subercaseaux concuerdan con la lectura que realiza Lucía Guerra respecto de la posición subordinada de la mujer en Occidente y, especialmente, en Chile. Para Guerra, la mujer se

\footnotetext{
${ }^{4}$ En el prólogo de Barco ebrio (1963) se sostiene que el poemario: "[...] surge al influjo de un cuarteta de Rimbaud: "La tempestad bendijo mi despertar marino" (3). Ciertamente, ese verso se entronca con el inicio del poemario de Reyes: "DENTRO de mí hay un viejo lobo de mar/ el buen piloto de un bergantín negrero" (4). La comunión de Reyes y el mar es establecida desde el génesis de su proyecto escritural.

5 Anthony Giddens establece que el amor-pasión implica una conexión genérica entre el amor y la atracción sexual: "El amor apasionado está marcado por una urgencia que lo sitúa aparte de las rutinas de la vida cotidiana, con las que tiende a entrar en conflicto" (Giddens, 43-44).
} 
encuentra inserta en un sistema patriarcal organizado a partir de la división del trabajo, el principio de la propiedad privada y la familia nuclear que determinó la subordinación de la mujer tanto en el área económica como en la cultural. A partir de la lectura de El segundo sexo de Simone de Beauvoir, Guerra concluye que la posición desmedrada de la mujer responde, fundamentalmente, a un problema valórico:

[...] la diferencia en las actividades asignadas a cada sexo se insertó en un sistema axiológico, en el cual se dio superioridad al sexo dedicado a matar y competir, devaluando de esta manera a la mujer. Por consiguiente, el desplazamiento económico y social de la mujer en la evolución histórica responde a la implantación de valores patriarcales fundamentados básicamente en la fuerza física, el falo, y el artefacto manufacturado (Guerra, Mujer, 15).

La producción literaria porteña de la época se hace cargo de la escisión entre hombres y mujeres, identificando a la mujer con la tierra y a los hombres con el mar. Carlos Cassasus evidencia esa conexión en Altamar (1928), texto contemporáneo a los primeros relatos de Reyes: "Las mujeres,/ no deben navegar,/ son la tierra.../ los hombres el mar" (46-47). Salvador Reyes no está lejos de ese imaginario. De hecho las voces masculinas clarifican, en diversas ocasiones, la visión androcéntrica que poseen del mundo, así como sucede con Julio Moreno de Mónica Sanders, Roberto Camerón de El café del puerto y Pedro Velazco de Valparaíso, puerto de nostalgia.

Moreno es un capitán ballenero que evidencia diversos atributos masculinos en el desarrollo de Mónica Sanders. Aventurero, arriesgado, recio, es capaz de imponerse por medio de la violencia a los enormes cetáceos que caza en el mar o a una banda de delincuentes de un cerro. En este sentido, asume que la mujer simboliza la tierra que constriñe al sujeto masculino. Hay dos momentos en que esa conexión queda clara. Uno. Cuando relaciona al mar con la libertad y a la tierra con la prisión:

Moreno contemplaba en silencio al viejo lobo que iniciaba su retirada. Ahora abandonaba el barco de alta mar por un remolcador que cada tarde lo depositaría en el puerto; después abandonaría el remolcador por el muelle y más tarde la tierra se apoderaría de él definitivamente (Rojas, Mónica Sanders, 267-268).

Dos, cuando afirma que el hombre es libre y que debe transgredir el control que impone la mujer: "Era tal vez la impresión casi física de que un hombre no puede estar siempre preocupado de una mujer. Al fin y al cabo un hombre es libre, iqué demonios!" (239). Para Moreno, las mujeres solo pueden ser un complemento de la vida: "Para mí las mujeres han sido siempre el 'extra"' (214).

En El café del puerto Camerón sostiene que el fin de su relación con Olga responde a la pasibilidad de su examante, la que, ante su lógica emprendedora y aventurera de "hijo de inglés", se transforma en un obstáculo a sus ambiciones: "Lo más desesperante en la mujer es su indiferencia para las cosas que el hombre más estima; su pasividad, su falta de iniciativa. Por eso una parte de la mujer es siempre un peso muerto en la vida de un hombre activo y emprendedor como yo" (76-77). 
Camerón remarca las oposiciones binarias que se producen entre lo masculino y lo femenino: "Estoy acostumbrado a vivir de otro modo, a andar de un lado para otro, a mezclarme en donde haya peligro y novedad. Mi desgracia es estar enamorado de una mujer calculadora que, como todas, piensa que solo es posible vivir en la casita con un canario en la ventana" (76-77). Camerón establece, en definitiva, que la tensión con Olga responde a que la mujer es incapaz de asumir la conducta enérgica que anhela para su vida.

En Valparaíso, puerto de nostalgia Velazco asume una postura similar a la de Camerón. Para Velazco el hombre debe competir, luchar y vencer: "Lo importante para el hombre es trabajar, abordar empresas y vencer dificultades" (11). En su rol de comerciante Velazco apunta a derrotar a sus competidores en los negocios que emprende en la pampa: "Él había trabajado en el desierto, que hace a los hombres duros y combativos [...] iA él le apasionaba esa vida! Pelearse con los competidores, comprar barato y vender caro; forzar, en cierto modo, la suerte" (12). Bajo esta lógica, Velazco asume que las mujeres son objetos destinados a complacerlo, especialmente, en términos sexuales: "La verdadera misión de la mujer es satisfacer los instintos del hombre y mantenerlo así apto para la lucha por la vida. No hay que permitir que la mujer salga de ese papel" (11). El miembro del Club de los Fumadores de Pipa no se queda solo en el discurso. Cada vez que obtiene éxito en sus empresas se desplaza a los prostíbulos de Antofagasta.

La actitud del sujeto masculino de Reyes puede ser entendida a partir de los aportes que efectúa Pierre Bourdieu en La dominación masculina, debido a que la masculinidad implica un deber-ser condicionado por la necesidad de exhibir la virilidad, esto es, la "[...] capacidad reproductora, sexual y social, pero también como aptitud para el combate y para el ejercicio de la violencia" (68). Los hombres están obligados a ejercer la violencia como una forma de silenciar su propia vulnerabilidad. Bourdieau subraya que lo viril únicamente existe como tal cuando es validado y reconocido por otros hombres: "[...] al margen de todas las ternuras y de todas las benevolencias desvirilizadoras del amor, y manifiestan de manera evidente la heterotomía de todas las afirmaciones de la virilidad, su dependencia respecto a la valoración del grupo viril" (70). De allí que Bourdieu establezca que: "[...] la virilidad es un concepto eminentemente relacional, construido ante y para los restantes hombres y contra la feminidad" (71). Bajo esta lógica, se entiende que los discursos de Moreno, Velazco y Camerón sean dirigidos siempre hacia otros hombres, ya que persiguen la validación de sujetos que tiene una posición análoga a sí mismos.

En las antípodas de las convenciones sociales, históricas y literarias de la época, los personajes femeninos de la narrativa de Reyes asumen una posición independiente, liberal y sensual que rompe con el imaginario impuesto por las sociedades hispanoamericanas conservadoras de inicios del siglo XX. Lo anterior es posible apreciarlo al considerar la distancia o el rechazo que estas mujeres sienten frente a las figuras que -en términos de Guerra- definen la concepción androcéntrica de la mujer: la 
virgen María y ángel del hogar. Tanto las protagonistas de las novelas y cuentos porteños de Reyes (Olga, Dora y Mónica) como los personajes secundarios (Nelly, Sonia, Magdalena) tienen una relación problemática con el matrimonio y la maternidad.

La narrativa porteña de Reyes muestra una posición crítica frente al matrimonio que puede ser analizada tanto desde la perspectiva de las mujeres solteras como de las casadas. Con relación al primer grupo, es posible sostener que existen varios personajes que mantienen distancia con el vínculo marital. Así, Sonia y Nelly de Valparaíso, puerto de nostalgia y Olga de "El café del puerto" no evidencian ningún interés en suscribir un contrato social que restrinja las liberales e intensas experiencias vitales que gozan en la noche de Valparaíso. Ahora bien, el quiebre con el anhelo de una "posición segura" -en términos de Rimbaud- alcanza un punto máximo en la figura de Dora en Piel Nocturna y Valparaíso, puerto de nostalgia ${ }^{6}$, debido a que, a diferencia de la ruta tradicional que seguían las mujeres de la década de 1930 y 1950, rechaza la posibilidad de contraer matrimonio. Ambos textos pueden ser leídos como novelas de (anti)formación que dan cuenta del proceso de crecimiento físico y espiritual de Dora. Empleo el término entre paréntesis porque la novela de formación apunta a integrar al sujeto en el mundo que enfrenta; los textos de Reyes, en cambio, plantean más bien un quiebre con las nociones tradicionales respecto del devenir femenino, así como plantea Berta López en su estudio sobre Hijo de ladrón. Al inicio de las novelas, Dora aparece como una "diablela"” al decir de Don Edgardo, es decir, una niña/mujer que seduce y tienta constantemente a los miembros del Club de Fumadores de Pipa:

Llegaba dos o tres noches a la semana; besaba a Elías, besaba a Fernando, disparaba su boina y se tendía en el diván [...] Don Edgardo acudía cada vez que sospechaba la presencia de Dora. Ella se sentaba en las rodillas del viejo, le rozaba la piel de cocodrilo con su piel delicada y, cuando ya lo tenía encendido y loco, se le escurría entre las manos [...] Dora tenía una manera de mirar, una malicia secreta en las palabras, una risa tan golosa (40-41).

La historia de ambas novelas tiene como uno de sus puntos centrales la transformación en mujer de Dora. Reyes construye parte importante del relato en torno al enigma que supone la "virginidad" de la muchacha. Ahora bien, el trayecto de esta "virgen loca" tiene dos vías de desarrollo: el matrimonio que le ofrece Eduardo, marino, miembro del Club de los Fumadores de Pipa o abrirse a la exploración de los placeres de

\footnotetext{
${ }^{6}$ Valparaíso, puerto de nostalgia (1955) es la traducción al español de Valparaíso, port de nostalgie (1947) editado en París, el que, a su vez, es el resultado de la traslación y modificación de Piel nocturna (1936).

${ }^{7}$ La "diablela" se relaciona con la idea de "nínfula" propuesta en Lolita (1955) por Vladimir Nabokov. En la novela se establece que las "nínfulas" son adolescentes que poseen un poderoso atractivo erótico para cierta clase de hombres: "[...] son muchachas, entre los nueve y los catorce años de edad, que revelan su verdadera naturaleza, que no es humana, sino la de las ninfas (es decir, demoniaca), a ciertos fascinados peregrinos, los cuales, muy a menudo, son mucho mayores que ellas" (22-23). A pesar de que Dora sobrepasa en un año la edad límite de la "nínfula", cuenta con una poderosa carga sexual que resulta seductora para varios de los personajes de la novela, como Eduardo, por ejemplo, quien es mucho mayor que Dora.
} 
la carne con distintos hombres. La carta que Eduardo le escribe a Velazco -quien despierta el deseo en Dora- da cuenta de este conflicto: "[...] he pedido a Dora que se case conmigo. Es tan leal y tan verídica, que no ha querido fingir por mí un cariño que no siente. Me ha hablado con sinceridad, y yo he comprendido que no debo insistir" (Reyes, Piel nocturna, 115). El rechazo a la propuesta matrimonial responde al intenso anhelo de Dora de extremar el goce de la vida, deleitándose en el placer del cuerpo: "Lo que siento no es tal vez un deseo: es más bien como un aturdimiento, como una borrachera que me arrastra... iQuisiera en estos momentos hacer todas las locuras [...] Entregarme a los hombres que me desean, emborracharme, gozar terriblemente!" (82). Dora es incapaz de contener el impulso que la lleva a experimentar con la delectación del erotismo. Así, consuma la metamorfosis anunciada en la presentación del libro en términos de que la "virgen loca" no acaba por convertirse en el "ángel del hogar" sino más bien en un "ángel caído" que degusta de la piel nocturna.

Ciertamente, resulta significativo considerar la actitud de Dora frente a la posición de un personaje icónico de la literatura femenina del mismo período: María Eugenia de Ifigenia (1926). En esta novela, Teresa de la Parra hace a la protagonista elegir -al igual que Dora- entre dos caminos: el "legítimo" y el "ilegítimo". Mientras el primero implica el matrimonio, la maternidad y el respeto social, el segundo el "concubinato" y, en consecuencia, una condición de "amante" que no se ajusta a su condición de "mujer de bien". María Eugenia termina, en definitiva, renunciando a la ropa, el maquillaje y la escritura, claudicando al: "Monstruo sagrado de siete cabezas que llaman: sociedad, familia, honor, religión, moral, deber, convenciones, principios" (368).

Reyes no construye matrimonios convencionales en sus relatos. Menos aún apegados a la "vieja moral". Magdalena Latour y Mónica Sanders terminan asumiendo posiciones elusivas o transgresoras frente a las obligaciones que demanda un vínculo de esta naturaleza. En Valparaíso, puerto de nostalgia Reyes dedica un capítulo a un personaje que había sido excluido de Piel nocturna, Latour, poeta que, luego de abandonar los parámetros de la vida convencional, opta por sumirse en la libertad y los excesos del arte. A partir de la visita que le realizan dos miembros del Club de Fumadores de Pipa, Reyes descubre la "escandalosa" trayectoria de la poeta:

Latour era uno de los nombres predilectos de las comadres porteñas: comentarios incansables y escandalizados rondaban en torno a sus viajes por Europa, en los cuales había disipado toda su herencia; a su matrimonio, a su divorcio un año después, a su actual independencia en la sociedad de poetas y artistas, y sus versos sensuales que publicaba en revistas revolucionarias (46-47, cursivas nuestras).

Hay dos elementos que nos interesa destacar de esta cita. Uno, la actitud rupturista que supone la publicación de "versos sensuales" en cuanto reivindica la relación de la mujer con el cuerpo, relación abordada por los estudios de corte feminista desarrollados desde 1920 y profundizados en 1960, y que conecta a Latour con el gesto liberador que supone la escritura. Dos. El divorcio de Latour en cuanto supone un 
enorme conflicto para las chilenas hasta bien entrado el siglo XX. No por nada la ley de divorcio en Chile recién se promulgó en 2004. En el plano literario Casa Grande (1908) resuelve la crisis amorosa de la pareja protagónica mediante el asesinato de Gabriela y La última niebla (1935) de María Luisa Bombal acaba con la derrota de la protagonista, la que acaba aceptando su posición subordinada en la nación: "Lo sigo para llevar a cabo una infinidad de pequeños menesteres, para cumplir con una infinidad de frivolidades amenas, para llorar por costumbre y sonreír por deber. Lo sigo para vivir correctamente, para morir correctamente, algún día" (Bombal, 95). Latour elige una alternativa distinta. Rompe con su matrimonio y adopta un estilo de vida que contraviene las expectativas de la sociedad porteña de la época, siguiendo, motivada por la poesía "[...] un camino tan retorcido y tan sembrado de improvistos" (Reyes, Valparaíso, 46-47). Asumiendo una posición subversiva apunta a escandalizar a las mujeres y los hombres que se vinculan con ella: "[...] encendió un cigarrillo [...] y empezó a hablar de poesía. Poco satisfecha del resultado de sus teorías, que parecían no alarmar a los demás, propuso: -Debemos ingeniarnos para obtener opio" (47).

El divorcio feliz de Latour anticipa uno de los episodios más significativos de la novela feminista del siglo XX en Latinoamérica: la publicación de La brecha en 1961. Mercedes Valdivieso construye la historia de una mujer -innominada- que se casa debido a que: "Antes de los veinticinco años debía adquirir un hombre -sine qua non- que velara por mí, me vistiera, fuera ambicioso y del que esperara, al cabo de cierto tiempo, una buena posición: la mejor posible" (13). Valdivieso está interesada en configurar el relato de una sedición en términos de que la protagonista se divorcia con el fin de terminar una relación asfixiante y, sobre todo, para realizarse personalmente. La autora explica que el escándalo que supuso la publicación de La brecha no responde tanto al quiebre del vínculo sino a sus consecuencias: "[...] el escándalo no fue que en ella [...] hablara del divorcio, sino que se transformó en un divorcio exitoso para la protagonista" (citado en Larraín, 3). La disipada y lírica vida de Latour se entronca con la actitud rupturista de la protagonista de La brecha.

Mónica Sanders tiene, también, un estilo de vida que conmociona a la sociedad de la época. Principalmente, porque cuestiona al "antiguo régimen" hasta el punto de transformarse en el comidillo de la sociedad porteña: "[...] en vez de casarse con alguno de los pijes que la cortejaba [...] anduvo por ahí trastornando a jóvenes y viejos [...] $\mathrm{Al}$ fin el viejo Sanders, aburrido de tanto lío, la envió a Europa en compañía de una tía. Dicen que Mónica dejó a la señora en Suiza y se fue de juerga a París y Londres" (Reyes, Mónica Sanders, 60). Hermosa, rica, liberal, Sanders se convierte en la figura romántica que desafía el orden de las familias. En la novela homónima aparece como una mujer madura que podría considerarse como la proyección de Dora. Es más, en una conversación con Moreno confiesa un ímpetu juvenil análogo al de la muchacha: "Aquí, en Valparaíso y en Viña fui terriblemente joven, ¿sabes? Joven de una manera casi frenética. Me parecía que no tenía sentidos bastantes para gozar mi juventud" (Reyes, Mónica Sanders, 216). Ante los ojos de la comunidad porteña Sanders se 
encuentra en un momento de decadencia. La ruina económica, el declive de su belleza, la irrelevancia social han acabado por eclipsar su otrora radiante estampa. En ese contexto, aparece casada con el amigo de su infancia -otro rico caído en desgraciaPercy Roy. Si bien esto podría ser leído como una vuelta al orden de las familias, el atípico matrimonio con Roy acrecienta aún más el carácter disruptivo de Sanders. Lo anterior, obedece a que la mujer transgrede la mayoría de las directrices del matrimonio. Roy pone de manifiesto el inusual vínculo entre ambos:

- [...] Vivimos como usted ve, en perfecta armonía. Además entre Mónica y yo no hay ninguno de esos principios tan respetables, pero tan sórdidos, que hacen la fuerza y la grandeza de la vida familiar.

- ¿Qué principios?

-El de esclavizar el uno al otro, el de constreñirlo, el de hacerle sentir a cada minuto que la vida no es sino una cadena de obligaciones y responsabilidades. Además, nosotros no tenemos hijos (Reyes, Mónica Sanders,143).

El discurso de Roy es interesante porque subraya dos componentes rupturistas de Mónica Sanders: la maternidad y el adulterio.

A contrapelo de diversas consideraciones sociales, Sanders opta por excluir a los hijos de su vida familiar. Más allá de las apreciaciones de su esposo, no evidencia interés alguno por la maternidad. De hecho, parece mucho más preocupada de eludir la abulia que parece acecharla y de satisfacer los deseos que parecen consumirla. El gesto de Sanders es significativo, ya que contraviene tanto a la ley eclesiástica como la civil en cuanto a que ambos establecen que el matrimonio tiene como objetivo la procreación. La prosecución de la línea sanguínea es capital para el desarrollo de la familia y de la nación, sin embargo, Sanders está mucho más preocupada de su satisfacción personal que de cumplir con las exigencias de la sociedad, la Iglesia y el Estado. En Ciudad, género e imaginarios urbanos en la narrativa latinoamericana (2014) Lucía Guerra establece la transformación que experimenta la mujer tras contraer matrimonio: "[...] la mujer en su pasividad 'femenina' es el Objeto del Deseo que, después del matrimonio, se convertirá en madre y suplemento hogareño para el hombre" (Guerra, 199). La toma de posición de Sanders se proyecta hacia el resto de las mujeres que cruzan la narrativa porteña de Reyes. No es azaroso que ninguna de las otras protagonistas ni de los personajes secundarios sean madres ${ }^{8}$. El autor de Piel nocturna parece asumir que la maternidad es una pesada carga sobre la mujer. Más aún al considerar que el limitado desarrollo de los métodos anticonceptivos -que recién se masifican en la década de 1960- sume a las mujeres en permanentes ciclos de reproducción e incluso de muerte.

El adulterio de Sanders constituye un componente tanto o aún más transgresor que la distancia con la maternidad. Al margen de cualquier clase de temor a una

\footnotetext{
${ }^{8}$ La excepción la podría constituir Elenita, adolescente que, evidentemente, habría sido embarazada por Don Esteban en Valparaíso, puerto de nostalgia. Sin embargo, el embarazo no es confirmado en la novela.
} 
condena moral, social e incluso penal, Sanders se muestra imperturbable luego de engañar, por primera vez, a su esposo con Moreno: "Mónica procedía con tranquilidad y lentitud, alzando los cabellos lacios [...] él no pudo descubrir ni la más ligera huella de esa turbación propia de la mujer que acababa de entregarse a su amante" (Reyes, Mónica Sanders,182). Así, pasa por alto el rechazo que motiva el adulterio en la Iglesia católica y en el Código Penal de Chile, el que hasta 1953, es decir, dos años después de la edición del libro, establecía que una mujer descubierta yaciendo con un varón que no fuera su marido arriesgaba una pena de cárcel que iba desde los 61 días hasta los cinco años. Asimismo, el "honor conyugal" permitía matar a una mujer sorprendida in situ en los brazos de otro hombre. El desafío de Sanders a una de las normas más valoradas del sistema patriarcal implica la detonación de una poderosa carga disruptiva, sobre todo, porque opta por mantener una relación paralela:

Se encontraron, como de costumbre, en la trastienda de la modista en Viña. Estuvieron largos minutos estrechamente abrazados. Después él la poseyó con un ardor brutal y ella fue la exaltada gozadora de siempre. [...] Con la cabellera revuelta, el cigarrillo en los labios y las manos en las caderas, Mónica siempre tan distinguida, tenía un aire de sensual vulgaridad.

¡Cómo cambias! -exclamo Julio-. Yo nunca sabré cuántas mujeres hay en ti. (Reyes, Mónica Sanders, 264)

Durante la relación "ilegítima" que mantiene con Sanders, lo único que Moreno es capaz de comprender de la mujer es que disfruta intensamente la experiencia erótica, lo que marca un punto de quiebre con la representación de las mujeres de la época en la narrativa chilena, debido a que Sanders funciona no solo como objeto sino como sujeto sexual. Así, Sanders no solo participa en el deseo de los hombres -Roy, Moreno y otros- sino que exige su propio placer, contraviniendo, en consecuencia, la lectura que efectúa Luce Irigaray en El sexo que no es uno: "Esta división del trabajo - en particular del trabajo sexual- requiere que la mujer mantenga, en su propio cuerpo, un sustrato material que la identifica como objeto del deseo, sin tener ella misma acceso al desear. La economía del deseo - del intercambio- es asunto de hombres" (189). El ardiente goce de Sanders reivindica un deseo femenino que, lejos de ponerse al servicio de la economía masculina, reclama su derecho a experimentar y disfrutar de la "carne". El tratamiento del erotismo de Sanders se extiende hacia la mayoría de las mujeres que cruzan la narrativa de Reyes: Olga, Dora, Sonia y Nelly viven, abiertamente, su sexualidad. En esta dirección, la posición de Nelly Bradford resulta concluyente: "Tengo treinta y cinco años. A los dieciocho conocí el amor físico. He vivido desde entonces de acuerdo con las doctrinas del amor libre. Para mí el sexo es una manera más de alegrar y embellecer la vida" (Reyes, Piel nocturna, 70). La reivindicación del deseo femenino y el rechazo a la maternidad permiten leer la erótica de Reyes a partir de dos conceptos que plantea Octavio Paz en orden a que el amor y el erotismo ponen: "[...] entre paréntesis el instinto sexual de procreación" (126) y a que los rituales eróticos asumen que "[...] el placer es un fin en sí mismo o tiene fines distintos a la 
reproducción" (11). De manera análoga al trabajo que María Luisa Bombal realiza con Ana María en La amortajada (1938) Reyes quiebra la concepción asexuada de la mujer: "Transgrediendo los modelos de un deber-ser simbolizado por la Virgen María, como mujer desprovista de placer sexual (Aeiparthenos: por siempre virgen)" (Guerra, Introducción, 19).

Reyes construye mujeres que aúnan sensualidad y belleza. Las tres protagonistas de los relatos abordados en el corpus, es decir, Dora, Mónica y Olga dan cuenta de la ardiente fusión que se produce bajo la sombra de Venus. A lo anterior se suman varios de los personajes secundarios, como Sonia, Nelly o Magdalena. La descripción de la primera aparición de Olga en El café del puerto da cuenta de lo anterior: "Su cuerpo ondulaba con firmeza y la mirada de los tres hombres se le ceñían en el imposible intento de inmovilizarle las caderas. Insinuaba una sonrisa con las comisuras de los labios. Sabía que sus pasos iban enmarañando una selva de deseos" (72). La utilización de protagonistas hermosas no es inusual en la narrativa hispanoamericana de inicios y mediados del siglo XX. María Eugenia, protagonista de Ifigenia, se describe de la siguiente forma: "[...] he descubierto últimamente que esto de vivir tapiada siendo tan bonita como soy, lejos de ser humillante y vulgar parece por el contrario cosa de romance" (15); la protagonista de La última niebla se sorprende al reconocerse a sí misma: "[...] desnuda y dorada, me sumerjo en el estanque. No me sabía tan blanca y $\tan$ hermosa" (62); La brecha de Mercedes Valdivieso cuenta, en tanto, la historia de una mujer de: "[...] diecinueve años, voluntad firme, pasión, belleza" (13).

Ahora bien, no se puede soslayar que el cruce de belleza y sensualidad evoca la imagen de la vampiresa del cine de las décadas de 1920 y 1930. Para Isabel Mozón la vampiresa es la mujer: "[...] que extrema el refinamiento de sus atributos para interesar y rendir a los hombres o a aquella de gran atractivo físico, con gran poder sobre el varón. La vampiresa es, a todas luces, una figura erótica que alimenta, con su imagen y sus conductas, el deseo del otro" (Monzón, en línea). La opción de Reyes está en relación con el trabajo de varias escritoras de la época. La infiel Regina de La última niebla tiene rasgos identitarios que se enmarcan en la femme fatale del film noir. Lo anterior no obsta, sin embargo, que la construcción psicológica de los personajes femeninos de Reyes esté lejos del reduccionismo propio de los estereotipos. Sanders revela un carácter "denso" -al decir de Todorov-, debido a que coexisten en ella atributos contradictorios que hacen imposible que pueda ser leída por su amante. Así, Sanders aparece en la novela como una mujer elegante/vulgar, altiva/sencilla, ardiente/fría, severa/alegre, madura/infantil, encantadora/despreciable, independiente/ desvalida, entusiasta/abúlica, es decir, una sola mujer parece condensar la totalidad del género femenino. El desenlace de la novela evidencia la incapacidad de Moreno para comprender su complejidad psicológica. Frente a la disyuntiva de partir al sur con su barco o quedarse en Valparaíso con su amante, elige viajar con el Alcatraz. Lejos de afrontar las consecuencias de su determinación, Moreno opta por ocultarle la verdad a Sanders, apelando a una mal entendida masculinidad: 
-¿Qué hago yo con una mujer que llora? ¡Prefiero tener delante a diez gallos armados de cuchillos!...

$-[\ldots]$ ¿Y si le anuncias a Mónica que te vas para siempre y no llora? [...]

-¡Tú estás loco, doctor; tú no sabes lo que dices! ¡Mónica está muy enamorada de mí y mi partida será un golpe horrible para ella! (Reyes, Mónica Sanders, 272-273).

Sanders no tarda mucho tiempo en enterarse del burdo engaño del marino. A diferencia del "valle de lágrimas" previsto por Moreno, Sanders mantiene su patrón de conducta con el ballenero durante el tiempo que le queda en Valparaíso. De hecho, Reyes anota hacia el final de la novela que Sanders acudía a las citas "[...] alegre y radiante" (Reyes, Mónica Sanders, 277). Antes de embarcarse Moreno descubre que Sanders supo, con mucha antelación, de su partida, lo que, evidentemente, le genera una enorme ira al descubrir que el "burlador" ha sido, finalmente, "burlado": "Ella sabía mi partida y fingió creer lo que yo le contaba: que me iba a quedar en el puerto... ¡Se ha burlado de mí la muy perra; pero yo le diré lo que se merece!" (289). Ciertamente, resulta interesante que Reyes reutilice un antiguo motivo literario, el "burlador-burlado" para mostrar la oposición que subyace entre la complejidad de Sanders y la liviandad de Moreno, quien, en términos de Todorov, es un personaje plano. La incapacidad del marino para comprender a su amante puede ser leída a partir de la reflexión de D. H. Lawrence acerca del carácter de la mujer, ya que no solo revela su extrañeza, sino, también, la generación de un ritmo que puede conducir hacia la compenetración o un quiebre irreconciliable: "Una mujer es una extraña y dulce vibración del aire que avanza, inconsciente e ignorada, en busca de una vibración que le responda" (citado en Deleuze y Guattari, 362). La concepción de la mujer como una extraña y dulce vibración resulta interesante porque Sanders, en su vida amorosa, persigue una respuesta que sea capaz de liberarla de la abulia que parece envolver su vida. A pesar de la conexión de la "came" que alcanza con Moreno, es evidente que el individualismo del ballenero hace imposible que dé con el tono que espera la mujer. Sin lágrimas, sin reproches, sin escándalos, Sanders dicta una lección de valor y dignidad que termina por descomponer a Moreno.

Las "porteñas" tienen la particularidad de vivir "afuera" del espacio doméstico. Lejos de estar circunscritas a los límites del hogar, se desplazan por las calles y cuestas de Valparaíso hacia los paseos, los clubes, los bares y los cabarets. A diferencia de los flaneurs de Baudelaire maravillados con los escaparates, las caminantes de Reyes parecen interesadas, más bien, en beber el encanto de un puerto nostálgico. La protagonista de Mónica Sanders da cuenta del vínculo con la ciudad: "He andado por Europa y por otras partes, pero aquí es donde yo he sido más feliz y más desgraciada. [...] Yo descubrí en Valparaíso el encanto de la calle, el rumor de la muchedumbre, lo pintoresco de la vida" (216). La vida en la cara externa de la urbe tiene enorme

\footnotetext{
${ }^{9}$ Schere sostiene que este motivo involucra " [...] la presencia de dos personajes antagonistas: en primer lugar, la figura del héroe astuto y victorioso; en segundo orden, la figura negativa del burlador-burlado, quien intenta engañar al héroe pero termina vencido por la inteligencia superior de su oponente" (21).
} 
importancia a la hora de considerar la posición de la mujer en la narrativa de Reyes, debido a que contraviene las convenciones sociales y genéricas de la primera parte del siglo XX. Guerra sostiene que el sistema de espacialización genérica utilizado por el régimen heterosexual crea a nivel material: "[...] un espacio propio para el hombre (ciudad) y para la mujer (casa) reforzando, así, los parámetros de una identidad adscrita" (Ciudad, 197). El predominio del espacio público se vincula con una producción de carácter masculino (la ciudad) y el espacio privado se conecta con la domesticación de la mujer y, por cierto, con la reproducción (casa). Así, la mujer queda situada en un espacio que equivale al repliegue y la interioridad: "En su rol primario de madre y esposa relegada en el ámbito doméstico, la praxis de la mujer está fuera de la noción prevalente de productividad concebida como el intercambio de trabajo por remuneración económica, razón por la que sus labores han recibido la denominación de trabajo invisible" (Ciudad, 168). Transgrediendo la conceptualización protectora e inmemorial de Bachelard, Guerra asume que la casa es un espacio regido por la estructura patriarcal que "[...] obliga a una existencia convencional bajo la cual se esconden anhelos e instintos que solo encuentran expresión en el ámbito natural donde aún perdura la vitalidad" (Mujer, 64). A partir de la imagen negativa del hogar, lo doméstico pasa a ser una verdadera "domesticación" de la mujer. La narrativa de Reyes escapa a la lógica de control falogocéntrica. Lo anterior responde a dos razones. Uno. La mínima presencia de la "casa" en la construcción del imaginario urbano. Dos. La irrupción de la mujer en el espacio público. Las "porteñas buenas mozas" recorren los diferentes espacios de la urbe, apropiándose de la ciudad, lo que acaba incrementando su nivel de libertad.

\section{CONCLUSIONES}

Salvador Reyes elabora un discurso femenino anárquico en su producción literaria porteña y, específicamente, en los términos políticos propuestos por Bakunin en Estatismo y anarquía, debido a que homologa las nociones de anarquía y libertad. Desde una perspectiva política, Bakunin afirma que la anarquía consiste en la liberalización de las masas laboriosas frente a la opresión generada por el Estado. No son las masas laboriosas las que experimentan la libertad en El café del puerto, Piel nocturna, Mónica Sanders y Valparaíso, puerto de nostalgia, sino mujeres que, en oposición al sistema patriarcal del Valparaíso de inicios y mediados del siglo XX, asumen posiciones transgresoras que socaban la "vieja moral". Así, cuestionan aspectos claves del orden de las familias: el matrimonio, la maternidad y el cerco doméstico, extendiendo los marcos de independencia que gozaban las mujeres hasta ese entonces. Distanciadas de las imágenes canónicas de la época - la virgen María y ángel del hogar-, escogen el desarrollo individual, el deleite de la carne y la utilización de nuevos espacios con el fin de erigirse como sujetos.

No se puede pasar por alto que aun cuando estamos frente a la presencia de un discurso generado por un hombre, la liberación femenina en el corpus estudiado llega más lejos que las apuestas escriturales de varias escritoras de la época, como, por 
ejemplo, las desarrolladas por María Luisa Bombal o Teresa de la Parra. Así lo demuestran el tratamiento del matrimonio, el adulterio, el divorcio y la maternidad. Sin embargo, hay un área clave en la autonomía femenina que no es desarrollada por Reyes: el ámbito económico. Aunque existen algunos personajes que trabajan -Dora, por ejemplo- siguen dependiendo, en líneas generales, del capital masculino. Solo tras la publicación de La brecha la imaginería literaria concebirá mujeres que detentan la capacidad económica para vivir al margen de la lógica de poder androcéntrica.

Reyes realiza, en cualquier caso, un importante avance en la representación de la autonomía femenina. Mujeres que se erigen no solo como objetos sino como sujetos de placer (Mónica, Dora, Nelly, Sonia, Olga), mujeres que rechazan la maternidad (Mónica, Dora, Nelly, Magdalena, Olga), mujeres que refutan su rol de esposas (Dora, Nelly), mujeres que se divorcian (Magdalena), mujeres adúlteras (Mónica), mujeres que consumen estupefacientes (Sonia) y mujeres que se abren a todos y todas (Nelly, Sonia). Siguiendo los pasos que da Rimbaud en Una temporada en el infierno, Reyes hace lo posible por evitar que los personajes femeninos sean devorados "[...] por brutos sensibles como fogatas" (66) con el fin de que puedan eludir el longevo peso de la noche masculina de Chile.

Universidad de Playa Ancha*

Centro de Estudios Avanzados Avda. Traslaviña 450, Viña del Mar (Chile) ivan.candia@upla.cl

Universidad de Playa Ancha** Avda. Playa Ancha 850, Valparaíso (Chile) oscar.rosales@alumnos.upla.cl

Universidad de Playa Ancha***

Centro de Estudios Avanzados Avda. Traslaviña 450, Viña del Mar (Chile) patricio.landaeta@upla.cl

\section{OBRAS CITADAS}

Avaria, Antonio. "Prólogo", en Ruta de sangre, Salvador Reyes. Santiago: Zig-Zag, 1998. Bakunin, Mijail. Estatismo y anarquía. Buenos Aires: Utopía Libertaria, 1989. Bombal, María Luisa. Obras completas. Santiago: Editorial Andrés Bello, 2000. Bourdieu, Pierre. La dominación masculina. Trad. Joaquín Jordá. Barcelona: Anagrama, 2000. Cassasus, Carlos. Altamar. Santiago: Editorial Nacimiento.1928.

Castagneto, Piero. El Valparaíso de los escritores. Santiago: RIL Editores, 2013. 
Del Solar, Hernán. “Mónica Sanders”. En: http://www.memoriachilena.cl/602/w3-article97700.html

De la Parra, Teresa. Ifigenia. Santiago: Zig-Zag, 1926.

Deleuze, Gilles y Guattari, Félix. Antiedipo. Capitalismo y Esquizofrenia. Barcelona: Paidós, 1985.

De Nordenflycht, Adolfo. "Valparaíso como espacio de la aventura en el imaginario de la narrativa imaginista". Atenea 504 (2011): 55-72.

Giddens, Anthony. La transformación de la intimidad. Sexualidad, amor y erotismo en las sociedades modernas. Trad: Benito Herrero Amaro. Madrid: Ediciones Cátedra, 1992.

Guerra, Lucía. Ciudad, género e imaginarios urbanos en la narrativa latinoamericana. Santiago: Cuarto propio, 2014.

_ “Introducción", en Obras completas, María Luisa Bombal. Santiago: Editorial Andrés Bello, 2000.

— Mujer y escritura. Fundamentos teóricos de la crítica feminista. México DF: Universidad Nacional Autónoma de México, 2007.

Irigaray, Luce. El sexo que no es uno. Trad. Raúl Sánchez. Madrid: Akal, 2009.

Larraín, Ana. "La extravagancia es el precio de mi libertad". El Mercurio, 18 de agosto de 1991: 1 y 4.

Latorre, Mariano. La literatura de Chile. Buenos Aires: Facultad de Filosofia y Letras de la Universidad de Buenos Aires, Instituto de Cultura Latino-Americana, 1941.

López, Berta. Hijo de ladrón, Novela de Aprendizaje Antiburguesa. Santiago: La Noria, 1987.

Melfi, Domingo. Estudios de Literatura Chilena. Santiago: Nascimento, 1938.

Montecinos, Manuel. "Salvador Reyes, el gran marinista". Disponible en: http://www.memoriachilena.cl/602/w3-article-70185.html

Montes, Hugo y Orlandi, Julio. Historia y analogía de la literatura chilena. Santiago: ZigZag, 1969.

Monzón, Isabel. Báthory. Acercamiento al mito de la Condesa Sangrienta. http://www.isabelmonzon.com.ar, consultado el 10 de septiembre de 2008.

Nabokov, Vladimir. Lolita. Santiago: Editorial Sol, 2006.

Reyes, Salvador. Barco ebrio. Antofagasta: Imprentas Unidas, 1963.

_ El café del puerto, en Los tripulantes de la noche, Salvador Reyes. Santiago: Andrés Bello, 1984.

_ Mónica Sanders. Santiago: Zig-Zag, 1951.

_ Piel nocturna. Santiago: Ediciones Ercilla, 1936.

— Valparaíso, Puerto de Nostalgia. Santiago: Zig-Zag, 1955.

Rimbaud, Arthur. Barco ebrio. Santiago: Dédalo, 1954.

— Una temporada en el infierno. Trad. Gabriel Celaya. Madrid: Visor Libros, 1985.

Schere, María Jimena. "El tópico del burlador-burlado en los caballeros de Aristófanes". Nova Tellus Vol. 30 (19-41).

Solar, Claudio. "Contactos literarios con Valparaíso". Atenea 453-454 (1986): 49-77. 
Porteñas buenas mozas: corazón y belleza en la construcción de la mujer

— Historia de la literatura de Valparaíso. Valparaíso: Ediciones de la Gran Fraternidad de Escritores y Artistas de la Costa, 2001.

Subercaseaux, Bernardo. "Masculino y femenino en el imaginario colectivo de comienzos del siglo". Revista Chilena de Literatura 42 (1943): 245-249.

Valdivieso, Mercedes. La brecha. Santiago: Zig-Zag, 1961. 